\title{
Ascorbic acid assisted synthesis, characterization and catalytic application of copper nanoparticles
}

\begin{abstract}
Herein, we report the synthesis of copper nanoparticles by simple, cost-effective, eco-friendly wet chemical reduction method using L-ascorbic acid as reducing agent. The synthesized nanoparticles were characterized by $\mathrm{X}$-ray diffraction, electron microscopy (SEM and TEM) and BET surface area analyzer. The surface area of $\mathrm{Cu}$ nanoparticles was found to be 10 times higher than the previous reports. The assynthesized $\mathrm{Cu}$ nanoparticles were used as catalyst for the degradation of Rhodamine $\mathrm{B}$ $(\mathrm{RhB})$ under both dark and light conditions. The $\mathrm{Cu}$ nanoparticles showed noteworthy enhancement in the degradation of RhB organic dye.
\end{abstract}

Keywords: $\mathrm{Cu}$ nanoparticles, synthesis, surface area, catalytic degradation, rhodamine B
Volume 2 Issue 4 - 2018

\author{
Ruby Phul, Chanmeet Kaur, Umar Farooq, \\ Tokeer Ahmad \\ Department of Chemistry, Jamia Millia Islamia, India
}

Correspondence: Tokeer Ahmad, Nanochemistry Laboratory, Department of Chemistry, Jamia Millia Islamia, New Delhi-I I0025, India, Tel 9I-I I-2698 I7 I7, Fax 9|-I I-26980229, Email tahmad3@jmi.ac.in

Received: February 01, 2018| Published: July II, 2018

\section{Introduction}

The fabrication, designing and manipulation of materials within the dimensions of $1-100 \mathrm{~nm}$ could be termed as nanomaterials. Nowadays nanomaterials are being used in various fields of physics, chemistry, biology, engineering etc. ${ }^{1,2}$ The major advantage of nanomaterials is that their properties changes drastically from bulk material of the same composition. The properties of nanoparticles could be easily altered by varying their size, shape, and chemical environment. ${ }^{3}$ The earth-abundant and inexpensive metal and metal oxide nanomaterials have acquired significant attention of research community due to their potential applications in catalysis, ${ }^{4-6}$ sensors, ${ }^{7}$ antimicrobial activity, ${ }^{7-11}$ contrast agents etc. ${ }^{12}$ Among the inexpensive metal nanoparticles, copper nanoparticles have attained attentions because of their interesting and high ultraviolet-visible sensitivity, thermal and electrical conductivity, and catalytic properties as compared to metallic gold and silver nanoparticles.

Several chemical routes viz. reverse micelles, ${ }^{13}$ solvothermal, ${ }^{14}$ hydrothermal, ${ }^{15}$ citrate precursor $^{16}$ methods etc. were reported in literature for the fabrication of numerous nanostructures. Copper nanoparticles could be synthesized through different techniques such as metal vapour synthesis, ${ }^{17}$ exploding wire method, ${ }^{18}$ sonochemical reduction, ${ }^{19}$ chemical reduction ${ }^{20-22}$ and microemulsion techniques. ${ }^{23}$ Among all these methods the chemical methods are of foremost importance because during the reaction copper nanoparticles oxidize to form thermodynamically stable copper oxide and to avoid oxidation, the reactions were carried out in inert media such as argon, nitrogen and also by using reducing, capping or protecting agents for the reduction of copper salt used. ${ }^{24-26}$ In the chemical reduction method conventional expensive and toxic reducing agents have been used for the reduction of metal ions to zero valent metal. ${ }^{27}$ To avoid the toxic effects we have used ascorbic acid as a reducing agent which also acts as a protecting agent to cease the oxidation reaction.

Rhodamine $\mathrm{B}(\mathrm{RhB})$ is a heterocyclic fluorescent dye used as a colorant in textile and food industries. It is also known for water tracer fluorescent. ${ }^{28}$ Being carcinogenic and toxic in nature, it adversely affects the humans and animals. ${ }^{29}$ The textile and food industries were constantly discharging this toxic dye in the form of effluents in water and increasing the problem of water contamination. ${ }^{30}$ In the present work, we have used the as-synthesized $\mathrm{Cu}$ nanoparticles for the catalytic degradation of $\mathrm{RhB}$ dye in dark as well as light conditions and it was found that the $\mathrm{Cu}$ nanoparticles were highly efficient for the degradation of organic pollutant.

\section{Experimental section}

\section{Materials}

Analytical grade chemicals were used throughout the experiment unless otherwise stated. All the chemicals were used as received without further purification. Copper (II) acetate monohydrate (98\%), L-Ascorbic acid (99\%) and Ethanol (99.9\%) were procured from Merck India Ltd. Double distilled water was used throughout the experiments. All the glass wares were washed thoroughly with nitric acid followed by distilled water.

\section{Synthesis of copper nanoparticles}

In a typical procedure $0.05 \mathrm{M}$ Copper (II) acetate was taken in a beaker and heated the solution at $90{ }^{\circ} \mathrm{C}$ on an oil bath with constant stirring. The color of the solution changes from royal blue to colorless (at $90^{\circ} \mathrm{C}$ ). At this moment $0.6 \mathrm{M} \mathrm{L}-$ Ascorbic acid solution was added dropwise to the above solution with vigorous stirring. The mixture was kept at $90{ }^{\circ} \mathrm{C}$ until a dark brown colored precipitate was obtained. To collect the precipitates, the dispersion was centrifuged at $8000 \mathrm{rpm}$ for $20 \mathrm{~min}$ and washed them 2-4 times with double distilled water and finally with ethanol. The collected precipitate was dried in an oven at $90{ }^{\circ} \mathrm{C}$ and ground to the powder. The detailed procedure for the synthesis of copper nanoparticles is shown in Figure 1.

\section{Characterization techniques}

The Rigaku Ultima IV with Ni-filter (for $\mathrm{Cu}-\mathrm{K} \alpha, \lambda=1.5416 \AA$ ) powder X-ray diffractometer was used at the step size of $0.05^{\circ}$ and step time of $1 \mathrm{sec}$, from $10^{\circ}$ to $80^{\circ}(2 \theta)$. The $\mathrm{K} \alpha 2$ reflections were removed by a normal stripping procedure to obtain the accurate lattice constants. The morphology of the synthesized nanoparticles was determined by JSM 6390 LV scanning electron microscope (SEM; JEOL, Tokyo, Japan). FEI-TECHNAI G² 20 Transmission electron microscope (TEM) was used to determine the shape and size of asacquired nanoparticles at the accelerating voltage $200 \mathrm{kV}$. The TEM 
measurements were done by placing a drop of sonicated sample on a carbon coated copper grid. The surface area and the pore size of assynthesized nanoparticles were determined using BET surface area analyzer (Model: Nova 2000e, Quantachrome Instruments Limited, USA) at liquid nitrogen temperature $(77 \mathrm{~K})$. Approximately $0.06 \mathrm{~g}$ of the samples was degassed at $90{ }^{\circ} \mathrm{C}$ for $3 \mathrm{~h}$ in a vacuum degassing mode to remove the surface contaminants. The degassed sample was then subjected for the analysis and the data was recorded by admitting known quantities of adsorbing $\mathrm{N}_{2}$ gas into the powder sample. As the adsorption occurs, the pressure in the cell changes until the equilibrium was attained. The specific surface area was calculated using the multipoint BET equation. The pore size distributions were determined from the $\mathrm{N}_{2}$ desorption isotherms at $77 \mathrm{~K}$, using the Dubinin-Astakhov (DA) method.

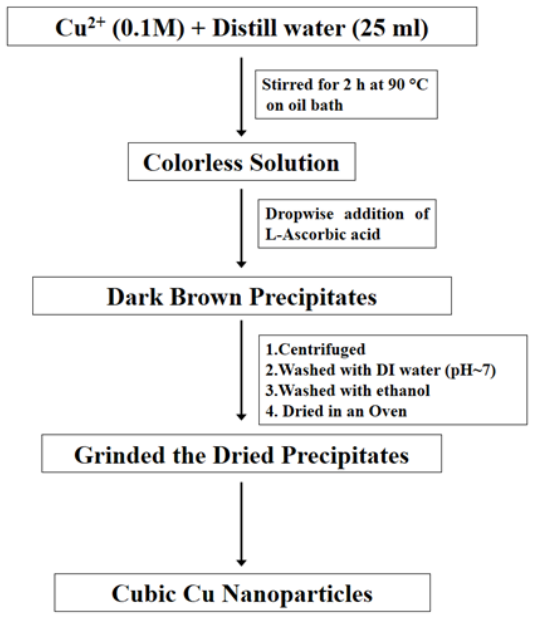

Figure I Schematic representation of synthesis of Cu nanoparticles.

\section{Catalytic measurements}

The catalytic efficiency of copper nanoparticles was measured against the degradation of Rhodamine $\mathrm{B}(\mathrm{RhB})$ dye under the dark and light conditions. The degradation process was studied by UVVis spectrophotometer (Agilent 8453) by analysing the change in absorption maxima $\lambda_{\max }=553 \mathrm{~nm}$ of RhB. $0.5 \mathrm{mg}$ of $\mathrm{Cu}$ nanoparticles was dispersed in $20 \mathrm{~mL} \mathrm{RhB}\left(1 \times 10^{-5} \mathrm{M}\right)$ and $0.5 \mathrm{~mL}$ aqueous solution of $\mathrm{NaBH}_{4}(0.1 \mathrm{M})$ was added with constant stirring. The degradation process was carried out at room temperature at $\mathrm{pH}$ 7. Thereafter, the catalytic process was checked in dark as well as in light conditions. In every 5 min interval an aliquot was taken to study the absorption spectra. The catalytic degradation reaction of $\mathrm{RhB}$ dye was also checked in the presence of $\mathrm{NaBH}_{4}$ only. All the experiments were repeated three times with excellent agreement.

\section{Results and discussion}

The phase crystallinity and structural analysis of the assynthesized copper nanoparticles was done by powder X-Ray diffraction technique. Figure 2 represents the diffraction pattern of $\mathrm{Cu}$ nanoparticles in which the peaks at $2 \theta$ value of $43.28^{\circ}, 50.40^{\circ}$ and $74.81^{\circ}$ correspond to (111), (200) and (220) planes respectively, confirms the cubic lattice of copper. All the diffraction peaks are in good agreement with the standard pattern for pure face centred cubic phase of copper nanoparticles (JCPDS No. 040836). No impurity peaks of $\mathrm{CuO}$ or $\mathrm{Cu}_{2} \mathrm{O}$ were observed. The very intense peaks indicating the highly crystalline nature of sample and the significant broadening of peaks attributed to the nanocrystalline nature of particles.

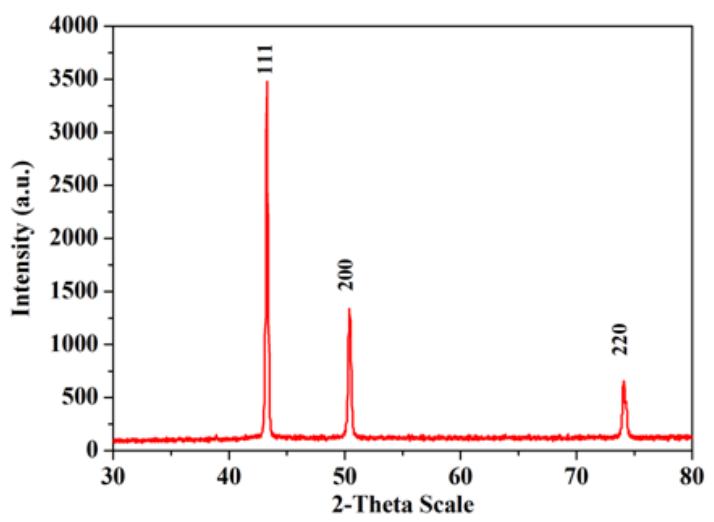

Figure 2 x-Ray diffraction patterns of copper nanoparticles.

The surface morphology of the as-synthesized nanoparticles was estimated by Scanning electron microscopic studies, as shown in Figure 3. The SEM image clearly indicates that the particles were very small in size and spherical in shape. The SEM image shows slight agglomeration of nanoparticles which could be attributed to the electrostatic attraction between the as-synthesized nanoparticles.

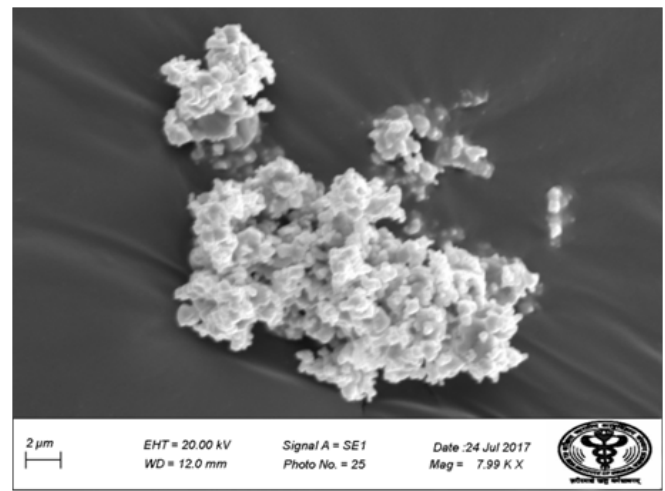

Figure 3 SEM image of copper nanoparticles.

The particle size of the as synthesized copper nanoparticles was examined by transmission electron microscopy (TEM). The TEM micrograph of as-synthesized copper nanoparticles is shown in Figure 4a. The TEM micrograph confirms the formation of monodispersed spherical $\mathrm{Cu}$ nanoparticles. The size of the as-synthesized nanoparticles was found to be in the range of $1-5 \mathrm{~nm}$ with an average grain size of $3 \mathrm{~nm}$. Figure $4 \mathrm{~b}$ shows the size distribution histogram of the as-synthesized $\mathrm{Cu}$ nanoparticles.
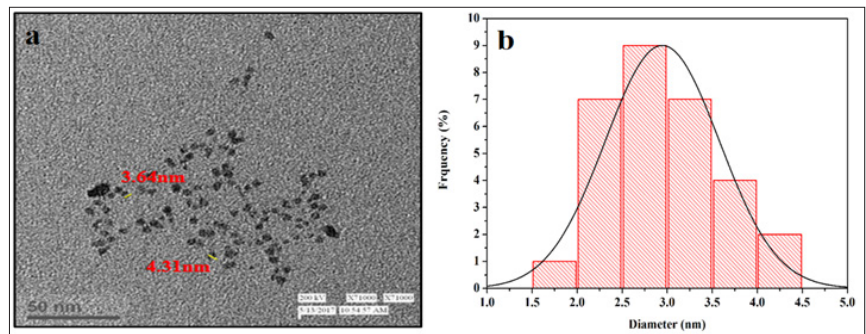

Figure 4 (a) TEM micrograph and (b) size distribution histogram of copper nanoparticles. 
Surface area plays an important role to determine different properties of the material, for example with increase in surface area the catalytic properties of nanoparticles are enhanced to the large extent due the availability of more surface-active sites. Therefore, to find the application of as-synthesized $\mathrm{Cu}$ nanoparticles as a catalyst it becomes imperative to analyse the surface area of nanoparticles. The surface area and the pore radius of as-synthesized $\mathrm{Cu}$ nanoparticles was determined by multipoint BET equation with relative pressure $\left(\mathrm{P} / \mathrm{P}_{\mathrm{o}}\right)$ in the range from 0.05 to $0.35 .{ }^{31}$ The specific surface area of these nanoparticles was found to be $365 \mathrm{~m}^{2} \mathrm{~g}^{-1}$ as shown in Figure 5a. The as-synthesized $\mathrm{Cu}$ nanoparticles show 10-time higher surface area as compared to the previous studies of $\mathrm{Cu}$ nanoparticles. ${ }^{32}$ Figure $5 \mathrm{~b}$ shows the DA plot, which determines the pore radius of $\mathrm{Cu}$ nanoparticles and it was found to be $\sim 15 \mathrm{~nm}$. The average particle size of nanoparticles is also estimated using surface area by assuming the particles have spherical shape and smooth surface using the equation:

$$
D_{B E T}=6000 /(\rho . S)
$$

where, $\mathrm{D}_{\mathrm{BET}}$ is the average diameter of the particles in nm, $\rho$ is the density in $\mathrm{gcm}^{-3}$ and $\mathrm{S}$ is the measured surface area of nanoparticle in $\mathrm{m}^{2} \mathrm{~g}^{-1}$. The average particle size was found to be $3 \mathrm{~nm}$ which is in support with the TEM results.

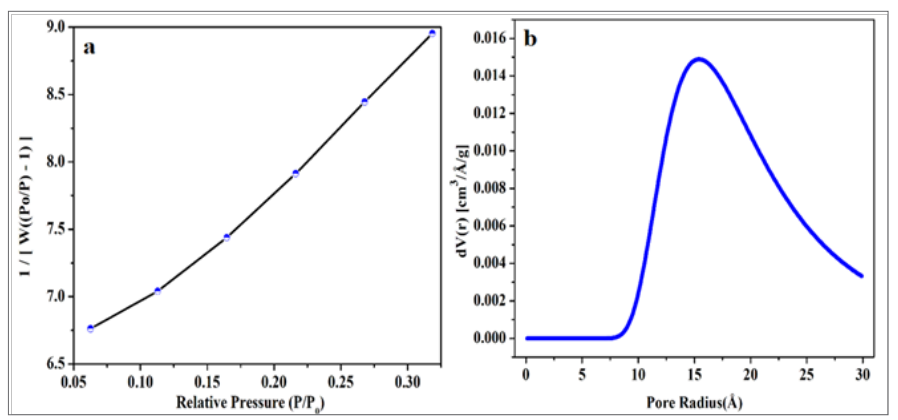

Figure 5 (a) BET plot and (b) DA plot of Cu nanoparticles.

\section{Photocatalytic activity}

The catalytic activity of as-synthesised nanoparticles was demonstrated by monitoring the degradation of $\mathrm{RhB}$ in the dark and light for $25 \mathrm{~min}$ and $15 \mathrm{~min}$, respectively. Figure 6a shows the UV-visible absorption spectra of catalytic degradation of RhB dye with $\mathrm{Cu}$ nanoparticles and $\mathrm{NaBH}_{4}$ in dark. A strong characteristic peak at $555 \mathrm{~nm}$ corresponds to the $\lambda_{\max }$ of $\mathrm{RhB}$ dye. In this report the degradation of $\mathrm{RhB}$ in presence of $\mathrm{NaBH}_{4}$ was studied in dark as well as in light using as-synthesized $\mathrm{Cu}$ nanoparticles as catalysts. From the studies it was observed that $\mathrm{Cu}$ nanoparticles take $25 \mathrm{~min}$ to completely degrade the RhB dye. Similar experiment was carried out in presence of sunlight and it was observed that in presence of sunlight the catalytic activity of the $\mathrm{Cu}$ nanoparticles is further enhanced as compared to dark conditions. In light conditions it was observed that $\mathrm{Cu}$ nanoparticles take much lesser time $(15 \mathrm{~min})$ to completely degrade the RhB dye. The UV-visible spectra of degradation reaction of $\mathrm{RhB}$ dye with $\mathrm{Cu}$ nanoparticles and $\mathrm{NaBH}_{4}$ in dark conditions and in presence of light is shown in Figure $6 \mathrm{a} \&$ Figure $6 \mathrm{~b}$ respectively. Figure 6a reveals that the characteristic peak of $\mathrm{RhB}$ appeared at 555 $\mathrm{nm}$ and in dark reaction conditions the peak intensity decreased with the time (till $25 \mathrm{~min}$ ). Similarly, figure $6 \mathrm{~b}$ represents the UV-visible spectra of $\mathrm{RhB}$ dye under sunlight, $\mathrm{Cu}$ nanoparticles and $\mathrm{NaBH}_{4}$, it was observed that intensity of characteristic peak at $555 \mathrm{~nm}$ decreases with increase in time (till $15 \mathrm{~min}$ ). The similar experiments were done for 60 min without $\mathrm{Cu}$ nanoparticles (i.e., with $\mathrm{NaBH}_{4}$ only) under dark and light conditions and no change in the intensity of absorption maxima of RhB was observed. So, it could be assumed that the degradation reaction takes place on the surface of the $\mathrm{Cu}$ nanoparticles which is further enhanced in the presence of sunlight. Since the synthesized nanoparticles were very small in size therefore the surface to volume ratio will be high providing more surface to enhance the catalytic property of the nanoparticles.
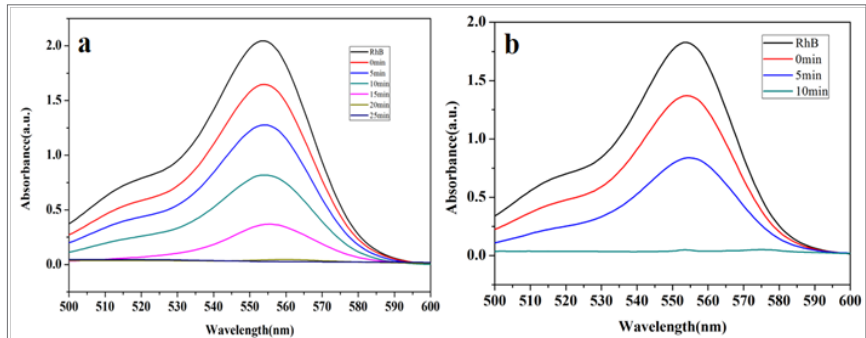

Figure 6 UV-visible absorption spectra of Cu nanoparticles (a) in dark and (b) in presence of sunlight.

The possible mechanism for photo-catalytic degradation of $\mathrm{RhB}$ dye by the $\mathrm{Cu}$ nanoparticles could be described by following equations: In

$$
\begin{aligned}
& \mathrm{Cu}+h v \rightarrow \mathrm{Cu}\left(e^{-}+h^{+}\right) \\
& \mathrm{Cu}\left(h^{+}\right)+\mathrm{H}_{2} \mathrm{O} \rightarrow \mathrm{Cu}+\mathrm{OH}^{\bullet}+H^{+} \\
& \mathrm{Cu}\left(h^{+}\right)+\mathrm{HO}^{-} \rightarrow \mathrm{Cu}+\mathrm{OH}^{\bullet}
\end{aligned}
$$

The electrons $\left(\mathrm{e}^{-}\right)$of $\mathrm{Cu}$ nanoparticles reduce the molecular oxygen $\left(\mathrm{O}_{2}\right)$ to hydroperoxyl radicals (i.e. protonated form of superoxide):

$$
\mathrm{Cu}+\mathrm{O}_{2}+e^{-} \rightarrow \mathrm{Cu}+\mathrm{O}_{2}^{\cdot-}
$$

So, the degradation of RhB dye could takes place either by the direct oxidation on the surface of photocatalysts or by hydroxyl radicals:

$$
\mathrm{OH}^{\bullet}+\mathrm{RhB} \rightarrow \mathrm{CO}_{2}+\mathrm{H}_{2} \mathrm{O} \text { (oxidized products) }
$$

Figure $7 \mathrm{a}$ shows the catalytic efficiency of as-synthesized $\mathrm{Cu}$ nanoparticles, which was calculated by plotting the change in relative concentration i.e. $\mathrm{C} / \mathrm{C}_{0}$ verses time for $\mathrm{RhB}$ dye under dark and light conditions. Further the percentage removal of dye was calculated by using equation:

$$
D(\%)=\left(C_{0}-C / C_{0}\right) \times 100
$$

The percentage removal of $\mathrm{RhB}$ dye from aqueous dye solution was shown in Figure $7 \mathrm{~b}$ and it was observed that $\mathrm{Cu}$ nanoparticles were able to removes $\approx 98 \%$ of dye within 15 mins when exposed to sunlight and in 25 mins in dark. There is found to be remarkable enhancement in the catalytic efficiency of $\mathrm{Cu}$ nanoparticles compared to the previous reports. ${ }^{33,34}$ The enhanced catalytic activity of assynthesized $\mathrm{Cu}$ nanoparticles could be attributed to the high surface area of nanoparticles as discussed in BET surface area studies. 

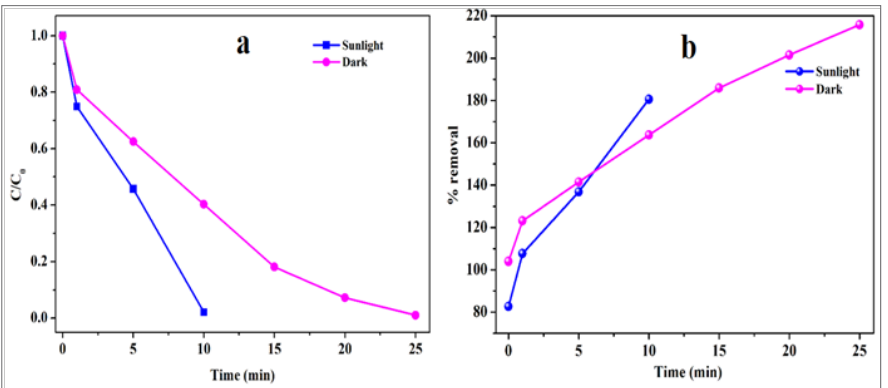

Figure 7 (a) Catalytic efficiency and (b) percentage dye removal of RhB dye with time using $\mathrm{Cu}$ nanoparticles in light and dark conditions.

\section{Conclusion}

We have successfully synthesized copper nanoparticles via simple wet chemical reduction route. The as-synthesized nanoparticles have cubic structure with an average particle size of $3 \mathrm{~nm}$. The synthesized nanoparticles have 10 times higher surface area as compared to the literature. The catalytic degradation of organic pollutant (RhB dye) was investigated on the surface of the $\mathrm{Cu}$ nanoparticles under both light and dark conditions and it was observed that the as-synthesized nanoparticles degrade $\approx 98 \%$ of dye. The acquired results suggest that the as-synthesized $\mathrm{Cu}$ nanoparticles could be used as effective catalyst for the degradation of organic pollutants in waste water treatment or environmental remediation.

\section{Acknowledgements}

TA thanks DST \& CSIR, New Delhi, Govt. of India for financial support. Authors are thankful to CIF, Jamia Millia Islamia for Xray diffraction studies, AIIMS, New Delhi for electron microscopy studies. UF and RP thanks to UGC for research fellowships.

\section{Conflict of interest}

Author declares there is no conflict of interest

\section{References}

1. Ozin GA. Nanochemistry: Synthesis in diminishing dimensions. $A d v$ Mater. 1992;4(10):612-649.

2. Shah MA, Ahmad T. Principles of Nanoscience and Nanotechnology. Narosa Publishing House, New Delhi, India; 2010.

3. Wani IA, Khatoon S, Ganguly A, et al. Silver nanoparticles: large scale solvothermal synthesis and optical properties. Mater Res Bull. 2010;45(8):1033-1038.

4. Gawande MB, Goswami A, Felpin FX, et al. $\mathrm{Cu}$ and $\mathrm{Cu}-\mathrm{Based}$ Nanoparticles: Synthesis and Applications in Catalysis. Chem Rev. 2016;116(6):3722-3811.

5. Ahmad T, Phul R, Alam P, et al. Dielectric, optical and enhanced photocatalytic properties of $\mathrm{CuCrO}_{2}$ nanoparticles. $R S C A d v$. 2017;7(44):2754927557.

6. Ahmad T, Chopra R, Ramanujachary KV, et al. Canted antiferromagnetism in copper oxide nanoparticles synthesized by the reverse-micellar route. Solid State Sci. 2005;7(7):891-895.

7. Zhang $\mathrm{H}$, Zhu Q, Zhang Y, et al. One-pot synthesis and hierarchical assembly of hollow $\mathrm{Cu}_{2} \mathrm{O}$ microspheres with nanocrystals-composed porous multishell and their gas-sensing properties. Adv Funct Mater. 2007;17(15):2766-2771.
8. Wani IA, Khatoon S, Ganguly A, et al. Structural characterization and antimicrobial properties of silver nanoparticles prepared by inverse microemulsion method. Colloid Surface B. 2013;101:243-250.

9. Wani IA, Ahmad T. Size and shape dependant antifungal activity of gold nanoparticles: a case study of Candida. Colloid Surface B. 2013;101:162170.

10. Cioffi N, Torsi L, Ditaranto N, et al. Copper nanoparticles/polymer composites with antifungal and bacteriostatic properties. Chem Mater. 2015; 17:5255-5262.

11. Ahmad T, Phul R, Khatoon N, et al. Antibacterial efficacy of Ocimum sanctum leaf extract-treated iron oxide nanoparticles. New J Chem. 2017;41(5):2055-2061.

12. Ahmad T, Phul R. Magnetic Iron Oxide Nanoparticles as Contrast Agents: Hydrothermal Synthesis, Characterization and Properties. Solid State Phenom. 2015;232:111-145.

13. Ganguly A, Ahmad T, Ganguli AK, et al. Self-assembly of Copper succinate nanoparticles to form anisotropic mesostructures. Dalton Trans. 2009;14(18):3536-3541.

14. Khatoon S, Ahmad T. Synthesis, Optical and Magnetic Properties of NiDoped ZnO Nanoparticles. J Mater Sci Engg B. 2012;2(6):325-333.

15. Ahmad T, Shahazad M, Phul R, et al. Hydrothermal Synthesis, Characterization and Dielectric Properties of Zirconia Nanoparticles. Mater Sci Eng Int J. 2017;1(3):1-5.

16. Ahmad T, Lone IH, Ansari SG, et al. Multifunctional Properties and Applications of Yttrium Ferrite Nanoparticles Prepared by Citrate Precursor Route. Mater Des. 2017;126:331-338.

17. Giovanni V, Maristella B. Nanoscale copper particles derived from solvated $\mathrm{Cu}$ atoms in the activation of molecular oxygen. Chem Mater. 2002; $14: 1183-1186$.

18. Tarasov S, Kolubaev A, Belyaev S, et al. Study of friction reduction by nanocopper additives to motor oil. Wear. 2002;252(2):63-69.

19. Kumar RV, Mastai Y, Diamant Y, et al. Sonochemical synthesis of amorphous $\mathrm{Cu}$ and nanocrystalline $\mathrm{Cu}_{2} \mathrm{O}$ embedded in a polyaniline matrix. J Mater Chem. 2001;11:1209-1213.

20. Khanna PK, More P, Jawalkar J, et al. Synthesis of hydrophilic copper nanoparticles: effect of reaction temperature. $J$ Nanopart Res. 2009;11(4):793-799.

21. Suárez Cerda J, Espinoza Gómez H, Alonso Núñez G, et al. A green synthesis of copper nanoparticles using native cyclodextrins as stabilizing agents. J Saudi Chem Soc. 2017;21(3):341-348.

22. Chandra S, Kumar A, Tomar PK, et al. Synthesis and characterization of copper nanoparticles by reducing agent. J Saudi Chem Soc. 2014;18(2):149-153.

23. Ahmed J, Trinh P, Mugweru AM, et al. Self-assembly of copper nanoparticles (cubes, rods and spherical nanostructure): Significant role of morphology on hydrogen and oxygen evolution efficiencies. Solid State Sci. 2011;13(5):855-861.

24. Jana NR, Wang ZL. Seed-mediated growth method to prepare cubic copper nanoparticles. Curr Sci. 2000;79(9):1367-1370.

25. Mott D, Galkowski J, Wang L, et al. Synthesis of size controlled and shaped copper nanoparticles. Langmuir. 2007;23(10):5740-5745.

26. Jeong S, Woo K, Kim D, et al. Controlling the thickness of the surface oxide layer on $\mathrm{Cu}$ nanoparticles for the fabrication of conductive structures by ink-jet printing. Adv Funct Mater. 2008;18(5):679-686.

27. Liu Y, Chu Y, Zhuo Y, et al. Controlled synthesis of various hollow $\mathrm{Cu}$ nano/microstructures via a novel reduction route. Adv Funct Mater. 2007;17(6):933-938. 
28. Richardson SD, Wilson CS, Rusch KA, et al. Use of rhodamine water tracer in the marshland upwelling system. Ground Water. 2004;42(5):678-688.

29. Kornbrust D, Barfknecht T. Testing of 24 food, drug, cosmetic and fabric dyes in the in vitro and in vivo/in vitro rat hepatocyte primary culture DNA repair assays. Environ Mutagen. 1985;7(1):101-120.

30. Soomro RA, Sherazi STH, Sirajuddin N, et al. Synthesis of air stable copper nanoparticles and their use in catalysis. Adv Mater Lett. 2014;5:191-198.

31. Brunauer S, Deming LS, Deming WE, et al. On a theory of the van der waals adsorption of gases. J Am Chem Soc. 1940;62(7):1723-1732.
32. Ponce AA, Klabunde KJ, et al. Chemical and catalytic activity of copper nanoparticles prepared via metal vapor synthesis. J Mol Catal A Chem. 2005;225(1):1-6.

33. Sohrabnezhad S, Karamzadeh M. Enhancement in visible light photocatalytic activity by embedding $\mathrm{Cu}$ nanoparticles over $\mathrm{CuS} / \mathrm{MCM}$ 41 nanocomposite. Appl Phys A. 2017;123:468.

34. Hamadanian M, Reisi Vanani A, Majedi A, et al. Synthesis, characterization and effect of calcination temperature on phase transformation and photocatalytic activity of $\mathrm{Cu}, \mathrm{S}$-codoped $\mathrm{TiO}_{2}$ nanoparticles. Appl Surf Sci. 2010;256(6):1837-1844. 